\title{
LEIAUTE (LAYOUT) E SUAS INTER-RELAÇÕES NOS SISTEMAS PRODUTIVOS
}

\section{ARTIGO ORIGINAL}

GÓES, Élida dos Santos ${ }^{1}$

ZORZENON, Rafael ${ }^{2}$

JOÃO, Plínio Gabriel ${ }^{3}$

ZANQUIM, Stivi Heverton ${ }^{4}$

GÓES, Élida dos Santos. ZORZENON, Rafael. JOÃO, Plínio Gabriel. Leiaute (layout) e suas inter-relações nos sistemas produtivos. Revista Científica Multidisciplinar Núcleo do Conhecimento. Ano 05, Ed. 01, Vol. 04, pp. 82-101. Janeiro de 2020. ISSN: 2448-0959, Link de acesso: https://www.nucleodoconhecimento.com.br/engenhariade-producao/leiaute

\section{RESUMO}

A decisão quanto a escolha do leiaute industrial é uma questão complexa, sendo que para a tomada dessa decisão é necessário a compreensão da operacionalização dos

\footnotetext{
${ }^{1}$ Graduada em Arquitetura e Técnica em Logística.

2 Doutorando em Engenharia de Produção; Mestre e Especialista em engenharia de produção pela UFSCAR. Graduado em Engenharia de Produção.

${ }^{3}$ Mestre em Processos de Ensino, Gestão e Inovação pela Uniara. Especialista em Finanças e Controladoria e Graduado em Administração de Empresas.

${ }^{4}$ Mestre em Comunicação pela Universidade Estadual Paulista - UNESP; Especialista em Publicidade e Mercado pela Universidade de São Paulo - USP e Graduado em Processos Gerenciais pela Universidade de Franca - UNIFRAN e em Propaganda, Publicidade e Criação com Habilitação em Marketing pela Universidade Presbiteriana Mackenzie.
} 
sistemas produtivos, que atendam à demanda do cliente e se alinhem às estratégias da empresa, assim como a análise das características das tipologias dos arranjos físicos. O objetivo deste trabalho é investigar a influência do arranjo físico nos processos produtivos. Para isso, foi realizado uma pesquisa bibliográfica exploratória visando um maior entendimento sobre os conceitos dos sistemas produtivos e o leiaute industrial, a fim de verificar a influência que esses elementos exercem. Os resultados demonstram que os aspectos da produção, volume e variedade, custos, investimentos em maquinários e pessoas, nível de serviço ao cliente, devem ser considerados ao adotar um tipo de leiaute. Pode-se concluir que o leiaute industrial adequado corrobora para a produtividade ao evitar movimentações desnecessárias, fluxos confusos, o que reduzirá os custos produtivos, elevando a competitividade das organizações empresariais.

Palavras-chave: Indústria, sistemas produtivos, leiaute.

\section{INTRODUÇÃO}

No contexto global competitivo, as organizações têm dentre vários objetivos a busca pela sustentabilidade empresarial, onde os aspectos econômicos, sociais e ambientais, que se satisfeitos eficiente e eficazmente, implicarão em melhores resultados no que tange à rentabilidade, a lucratividade, baixos custos e desperdícios, e, alcançando assim o bem-estar geral (SLACK et al, 2009).

Segundo Gonçalves Filho (2001) há quatro fatores para realização da eficiência na manufatura, são eles: a tecnologia, o arranjo físico otimizado, a mão de obra treinada e a gerência da produção eficiente. Em contraponto, as empresas sofrem problemas em sua maioria decorrente de um mau planejamento. De acordo com Slack et al (2009), o arranjo físico é um aspecto substancial no qual se refere à estruturação e implantação da indústria que se realizado de forma inadequada pode afetar, sobretudo, os processos e a produtividade.

Como forma de minimizar os custos logísticos, otimizar os processos produtivos e melhorar os fluxos, se faz necessário, dentre alguns aspectos que permeiam os 
processos de transformação (throughput), a análise sobre os tipos de arranjos físicos e suas inter-relações no ambiente da organização. Slack et al (2009) define arranjo físico como:

O arranjo físico de uma operação ou processo é como seus recursos transformadores são posicionados uns em relação aos outros e como as várias tarefas da operação serão alocadas a esses recursos transformadores. Juntas, essas duas decisões irão ditar o padrão do fluxo dos recursos transformados à medida que eles progridem pela operação ou processo. (SLACK et al,2009, p 182 e 183)

O objetivo deste artigo é investigar, através da literatura, a influência do arranjo físico nos processos produtivos. $\mathrm{O}$ artigo foi construído por meio de pesquisa bibliográfica exploratória realizada com os principais autores, bem como em trabalhos, artigos e teses referentes ao estudo, abordando os conceitos de sistemas produtivos e suas classificações, leiaute e os tipos básicos, a relação entre os processos produtivos e os tipos de leiaute, a escolha do tipo de leiaute e os tipos de leiaute para estoque.

\section{TIPOLOGIAS, CONCEITOS SOBRE OS SISTEMAS PRODUTIVOS E OS LEIAUTES}

A produção industrial é baseada na premissa do atendimento à demanda dos pedidos. O sistema produtivo implantado conota a estreita relação entre o planejamento estratégico e a sua organização física para o alcance das expectativas do cliente. Sendo os processos produtivos resultantes da decisão estratégica e do leiaute, se faz necessário a análise da literatura no tocante aos conceitos e tipologias dos sistemas produtivos industriais e dos arranjos físicos.

\subsection{SISTEMAS PRODUTIVOS E SUAS CLASSIFICAÇÕES}

Os sistemas produtivos são definidos como elementos transformadores de recursos de entrada (inputs) em saídas (outputs), de bens e serviços. (PIRES, 2009; SLACK et al, 2009; TUBINO, 2007). Com base nesse conceito, compreende-se como sistemas 
produtivos a entrada de recursos de materiais em uma organização, sua transformação e todos os processos envolvidos na produção até o momento de sua saída, em produtos de bens de consumo ou serviços.

A classificação dos sistemas de produção é apresentada por diferentes autores de diversas maneiras. Lustosa et al (2008) organizaram as formas mais comuns de classificação dos sistemas de produção de acordo com os critérios:

1. Grau de padronização dos produtos: produtos padronizados e personalizados

2. Tipo de operação: processos contínuos e processos discretos;

3. Ambiente de produção: MTS, MTO, ATO e ETO;

4. Fluxo dos processos: Processos por projetos, em linha, em lote;

5. Natureza dos produtos: produção de bens de consumo ou serviços.

Pires (2009) apresenta a classificação em que se relaciona com o cliente, tanto para as organizações de sistema empurrado e puxado através dos ambientes de produção: MTS, MTO, ATO e ETO.

- MTS (Make to Stock) - produção para estoque: baseada nas previsões de venda de acordo com o estoque de produtos acabados. A relação com o cliente é mínima, reduzida às pesquisas mercadológicas.

- MTO (Make to Order) - produção sob encomenda: baseada nos pedidos. Os produtos encomendados são customizados, o que gera complexidade para o processo de gestão. O cliente interfere no processo produtivo.

- ATO (Assemble to Order) - montagem sob encomenda: Há estoques de componentes comuns da produção para montagem do produto após a conclusão da venda. Minimiza os custos produtivos.

- ETO (Engeneering to Order) - engenharia sob encomenda: tem alta participação do cliente no processo. O processo se dá pelas vendas, projeto do produto, planejamento da produção, produção e entrega.

De acordo com Tubino (2007) e Lustosa et al (2008), os sistemas produtivos podem ser classificados pela natureza dos produtos: em manufatura de bens, para objetos 
físicos, e para produtos intangíveis, como prestadores de serviços. Para Lustosa et al (2008) e Tubino (2007) os sistemas são baseados na demanda produtiva, a saber:

- Sistema contínuo abrange a produção de bens de base, energia elétrica, petróleo, produtos químicos, e alguns serviços, como serviços de aquecimento e ar condicionado, sistemas de monitoramento por radar, limpeza contínua, serviços fornecidos via Internet. É facilmente automatizado devido a uniformidade dos produtos e serviços, porém devido a continuidade produtiva não permite desvincular os processos, tornando o sistema mais rígido para mudança e gerando produtos mais onerosos. Os investimentos são concentrados nos equipamentos, o custo da mão de obra é baixo.

- Sistemas em massa são aplicados à produção de produtos padronizados em larga escala, devem ter a participação de um colaborar diretamente. A produção bens de consumo são compostas pelas indústrias automobilísticas, eletrodomésticos, têxteis e de abate e beneficiamento de aves, suínos e bovinos, a prestação de serviços, pelas empresas de transportes aéreos, revistas e editoração de jornais. A variabilidade dos produtos é mínima, conferindo estabilidade ao sistema e linhas de montagem pouco flexíveis. $O$ volume de entrada de matérias primas é alto e a saída de produto acabado é em larga escala, com pouca diversificação, o sendo na montagem final por componentes padronizados, resultando em alto volume de estoques. A mãode-obra humana era pouco qualificada e pouco polivalente devido às operações repetitivas. Após o Toyotismo e a implantação da manufatura enxuta, a mão de obra tornou-se mais polivalente, o que reduziu o quadro de funcionário das organizações, o leiaute mais flexível, as atividades padronizadas mais eficientes, resultando numa produção enxuta baseada na demanda com tempo de ciclos maiores.

- Sistemas repetitivos em lote são caracterizados por produtos ou serviços padronizados em lotes de volume médios. É relativamente flexível, focado no atendimento do cliente e da demanda, o colaborador é mais polivalente, e o trabalho é dividido em departamentos, os equipamentos são pouco especializados. A produção em lotes econômicos dilui os custos do preparo do 
processo. Os estoques são voltados a atender os diferentes processos através de espaços estrategicamente alocados para abastecimento da produção. A produção é diversificada e com baixa sincronização. Esse sistema é composto por empresas que produzem componentes para indústrias de linha de montagem, sendo elas fornecedoras de cadeias automobilísticas, eletrodomésticos.

- Sistema sob encomenda é voltado para atender as necessidades específicas do cliente, de demandas baixas. A organização é feita de acordo com o projeto de cada produto novo, alinhado ao pedido do cliente. Dessa forma, os estoques intermediários não podem ser preparados com antecedência, devido a variação do projeto, excetuando a compra de matérias primas e outros componentes. Exige alta flexibilidade e maiores custos produtivos pertinentes ao atendimento especializado. Compõem esse grupo, fabricação de bens de consumo: aviões, navios, máquinas e ferramentas e a prestação de serviços, como arquitetura, agências de propaganda, escritório de advocacia. O trabalho é organizado baseado nas funções que serão executadas.

Slack et al. (2009) classificam os sistemas produtivos de acordo com os recursos a serem transformados e dos tipos de processos de transformação. Os processos em manufatura e em serviços são classificados de acordo com a relação das variáveis de volume e variedade. $\mathrm{Na}$ manufatura são denominados: processos contínuos, processos de produção em massa, processos em lotes ou bateladas, processos de jobbing e processos de projeto. Os processos em serviços são denominados em serviços profissionais, lojas de serviços e serviços de massa. Os processos de produção sofrem interferência das variáveis volume de produção e variedade de produtos, sendo que segundo Slack et al (2009) os processos são classificados em:

- Processos de projeto são caracterizados por baixo volume e alta variedade, tempo de produção longo. As atividades possuem início e final determinados, porém na execução, mal definidas e incertas, onde o processo pode sofrer alterações. À exemplo desses processos são a produção de filmes, construção naval, implementação de um sistema computacional. 
- Processos de jobbing a produção é de grande escala, de itens de tamanhos menores e tem o grau de repetição baixo. Os profissionais que trabalham sob encomenda, engenheiros especializados, mestres ferramenteiros, gráficas são exemplos de uso do processo de jobbing.

- Processo em lotes ou bateladas se dá pela repetição e padronização da produção, por rotas previsíveis, caracteriza-se por menor variedade em relação ao processo de jobbing. O tamanho do lote pode ser constituído de vários produtos, assim como único, configurando-se em altos níveis de volume e variedade. As produções de alimentos congelados, produção automobilística, manufaturas de máquinas são exemplos de processos em lotes.

- Processos de produção em massa, a produção constitui-se em alto volume e pouca variedade. No conceito de produção em massa não são verificadas as peculiaridades da produção, mas a estrutura básica para a produção. Seus processos são repetitivos e as atividades são sincronizadas, a exemplos da indústria automobilística, de eletroeletrônicos, processamento de alimentos.

- Processos contínuos, os volumes são maiores que a produção em massa, e a variedade menor. O tempo de produção é mais longo, o fluxo é ininterrupto e inseparável, sendo inflexível devido à tecnologia o que acarreta custo elevados, gerando estoques no processo. Esse tipo de processo não há margem para decisões estratégicas pois o controle produtivo é automático, assim acontecem nas produções das refinarias petroquímicas, centrais elétricas, fábricas de papel, entre outras.

Quanto aos serviços, Slack et al (2009) os classificam em três tipos, a saber:

- Serviços profissionais são caracterizados por serviços altamente customizados e personalizados de acordo com a necessidade do cliente, sendo que possui um elevado tempo de atendimento devido a compatibilização do serviço ao pedido do cliente, onde todas as decisões devem ser tomadas em conjunto, gerando serviços únicos, de acordo com as particularidades de cada cliente 
- Lojas de serviços são intermediárias em relação aos níveis de relacionamento com os clientes, customização, se comparadas aos serviços de profissionais e os de massa. Se dá pela combinação entre escritórios de linha de frente, onde oferece o produto em pontos de venda e de retaguarda, onde administra os mesmos. O escritório de linha de frente deve se utilizar do conhecimento técnico para estabelecer o relacionamento com o cliente ao vender o produto padronizado. Para a confiabilidade dos serviços é necessário o constante acompanhamento dos processos. As lojas, bancos, locadoras de veículos, restaurantes, hotéis e agentes de viagens são representantes das lojas de serviços.

- Serviços em massa atendem a altos volumes de clientes, com tempo limitado e customização mínima. O procedimento de atendimento é preestabelecido e baseado no produto. São exemplos desse serviço, supermercados, redes de telecomunicações, aeroportos, atendimento de serviço público.

Os diferentes critérios das classificações dos sistemas produtivos se consolidam pela relação dos elementos de entradas, processo de transformação e saídas, níveis de relacionamento com o cliente, a demanda, tempo de produção, volume e variedade produtiva, sendo que ao compreender as peculiaridades de cada sistema incide em melhores planejamentos para as produções objetivando a eficiência dos processos (LUSTOSA et al, 2008; SLACK et al, 2009; TUBINO, 2007).

\subsection{LEIAUTE E OS TIPOS BÁSICOS}

O leiaute ou arranjo físico de uma operação ou processo é composto pela posição física dos recursos transformadores, sendo eles materiais, informações e clientes, e sua relação com as operações (SLACK et al, 2009).

Segundo Gaither e Fraizer (2012), o projeto do leiaute objetiva o atendimento das necessidades dos clientes, tendo como resultado os produtos e serviços. Os leiautes industriais mais compactos são resultados de decisões estratégicas implicando sobre o desempenho da organização, reduzindo os custos e melhorando a movimentação, conferindo flexibilidade a produção. O planejamento do leiaute se dá pela distribuição 
dos equipamentos, setores e fluxo de informações no espaço, sendo interligado ao processo da produção.

O arranjo físico é relevante para as organizações, pois para Slack et al (2009) as situações problemáticas mais comuns no cotidiano das indústrias são decorrentes do leiaute equivocado, fluxos excessivos, longos e confusos, estoques de produtos desnecessários, filas de clientes, tempo de processamento moroso, operações inflexíveis. $O$ arranjo físico deficiente pode dificultar a movimentação dos volumes, o fluxo de materiais e clientes, restringir a organização de insumos, provocar acidentes. Sendo o leiaute a etapa inicial na implantação das indústrias, todas as decisões tomadas a nível de projeto afetarão o desempenho da organização futuramente, e um projeto equivocado pode se tornar oneroso, custando paradas na produção e dispêndio com novas adequações do espaço e instalações.

Segundo Gaither e Fraizer (2012), Moreira (1993), Slack et al (2009) e Stevenson (2001) o leiaute das organizações, ou arranjo físico, pode ser classificado em:

- Leiaute por posição fixa ou posicional é caracterizado por um produto ou serviço de grande porte que será trabalhado onde os materiais, máquinas, pessoas se movimentam em seu entorno. Essa movimentação, bem como o armazenamento dos materiais devem ser considerados no espaço a ser projetado. O planejamento e controle dos processos não permitem muitas variações, porém os custos administrativos são mais onerosos devido à complexidade dos mesmos. Possui baixa produção e padronização, produto único. Exemplos de leiaute posicional: construções de edifícios e equipamentos urbanos, construção naval, aeronaves e mísseis, reformas e reparos, atividades agropecuárias e de combate a incêndios. 
Figura 1 - Arranjo físico posicional

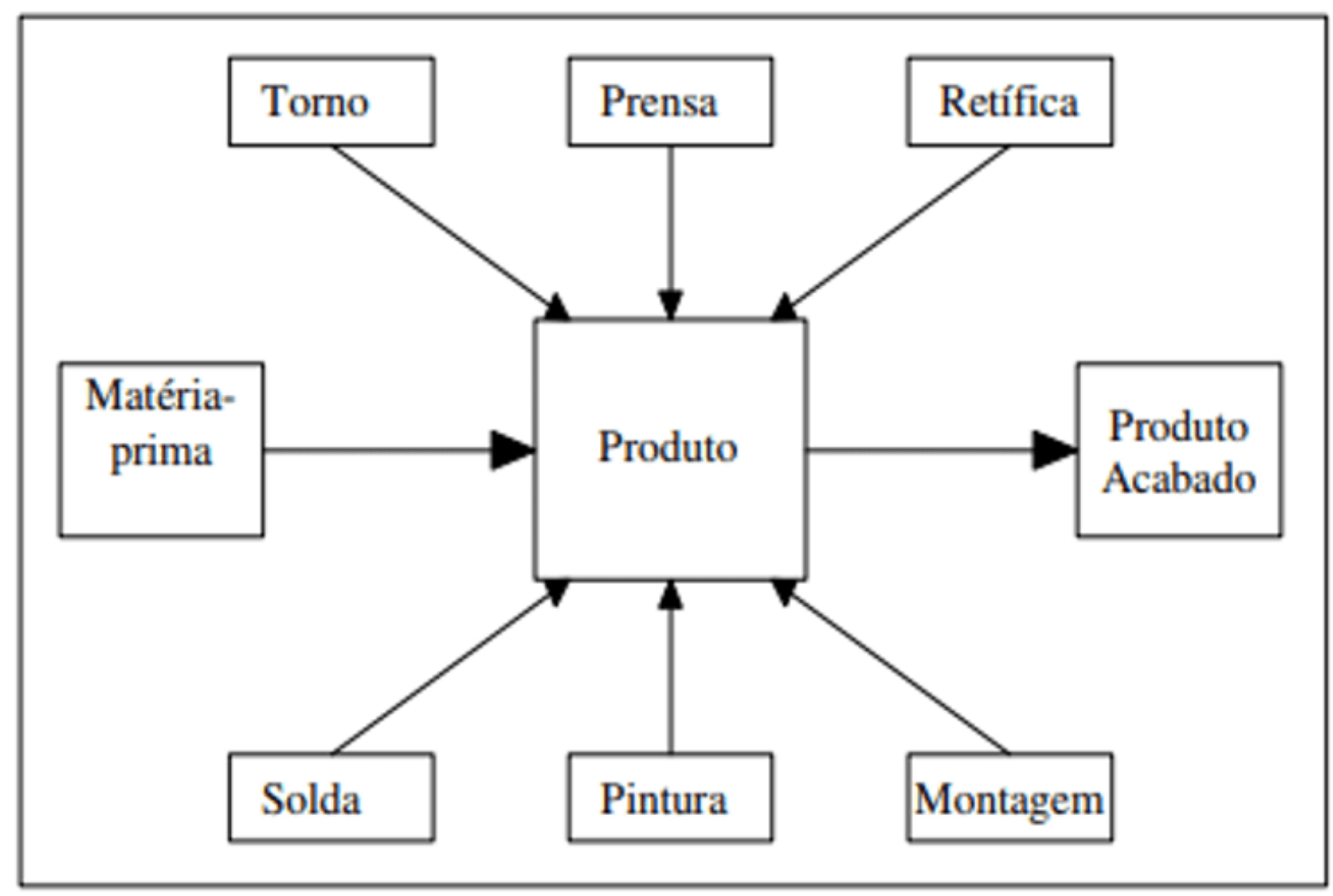

Fonte: Adaptado de ARGOUD (2007).

$\mathrm{Na}$ representação da figura 1, observa-se um produto sendo alimentado por insumos e processos que se moverão em seu entorno para resultar no produto final. Segundo Argoud (2007), essa composição é flexível pois admite mudanças no projeto.

- Leiaute por processos ou funcional é implantado conforme a necessidade das operações de processamento, no qual os recursos ou processos similares devem ser localizados próximos com o objetivo de facilitar o fluxo de materiais, informações e clientes. Esse leiaute se caracteriza por sua flexibilidade dos processos, podendo personalizar os produtos com produção de pequenos lotes, ênfase na movimentação através de empilhadeiras, os trabalhadores são mais especializados pois o planejamento, programação e controle deve ser contínuo para garantir as atividades dos diferentes processos. O tempo de produção é maior e possui estoques grandes, tem como vantagem equipamentos e manutenções de custos menores, no entanto o custo unitário 
do produto é maior. Os hospitais, supermercados, bibliotecas, indústrias de usinagem de peças utilizam o leiaute por processos.

Figura 2 - Arranjo físico funcional

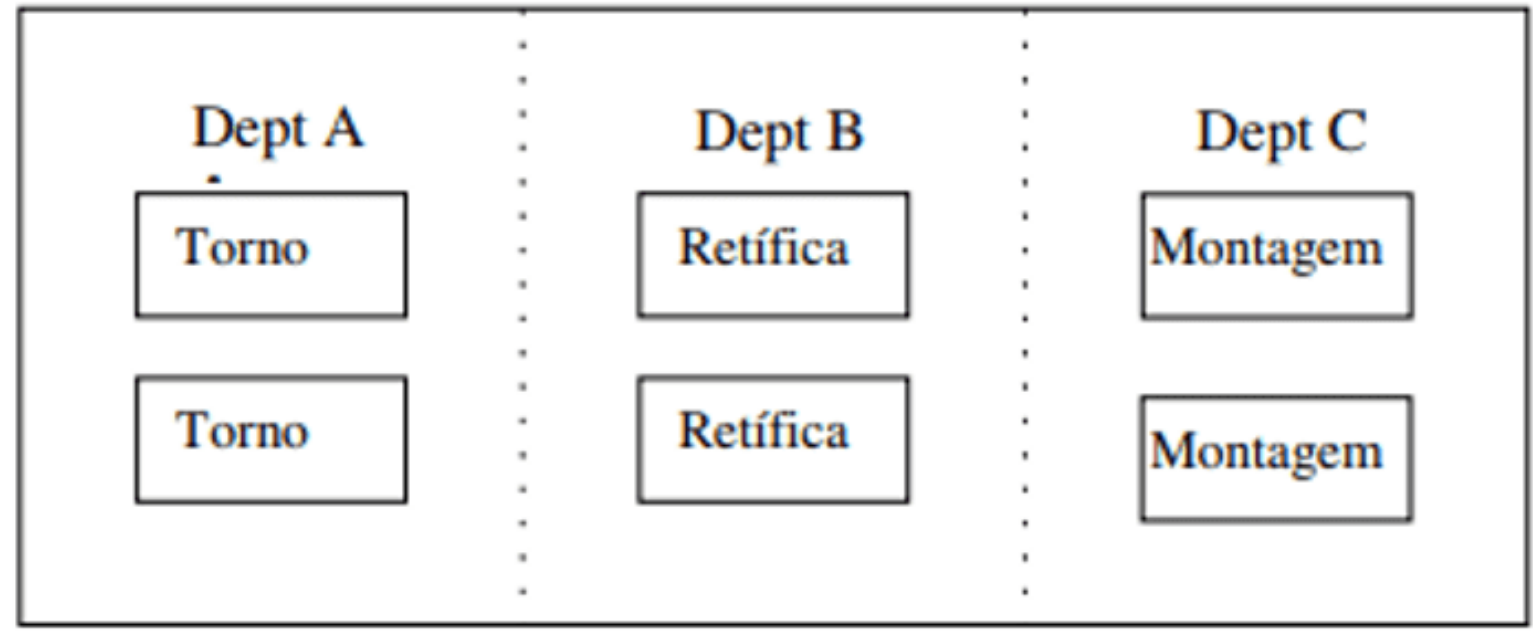

Fonte: Adaptado de ARGOUD (2007).

Na figura 2, a composição para o leiaute se dá por departamentos, por segmentação de processamento. Para Argoud (2007), esse arranjo físico apesar de ser flexível, apresenta baixa eficiência por envolver decisões de programação mais complexas.

- Leiaute por produtos é ideal para produção de poucos itens, sendo eles padronizados, e serviços uniformes. Caracteriza-se pelo fluxo veloz e de fácil identificação de bens ou clientes em grande escala. Os recursos que serão transformados são localizados em sequência de acordo com o processo de transformação. Os maquinários são especializados, o que acarreta alto custo de manutenção, em contraponto, o funcionário é pouco qualificado por desenvolverem poucas atividades e repetitivas. A configuração é rígida devido ao alto volume de produção, que diluirá o custo de produção unitário, porém suscetíveis a falhas e paralisações. Os principais exemplos de implantação desse leiaute são as indústrias automobilísticas, manufaturas de eletrodomésticos e âmbito dos serviços, o alistamento no exército. 
Figura 3 - Arranjo físico por produto

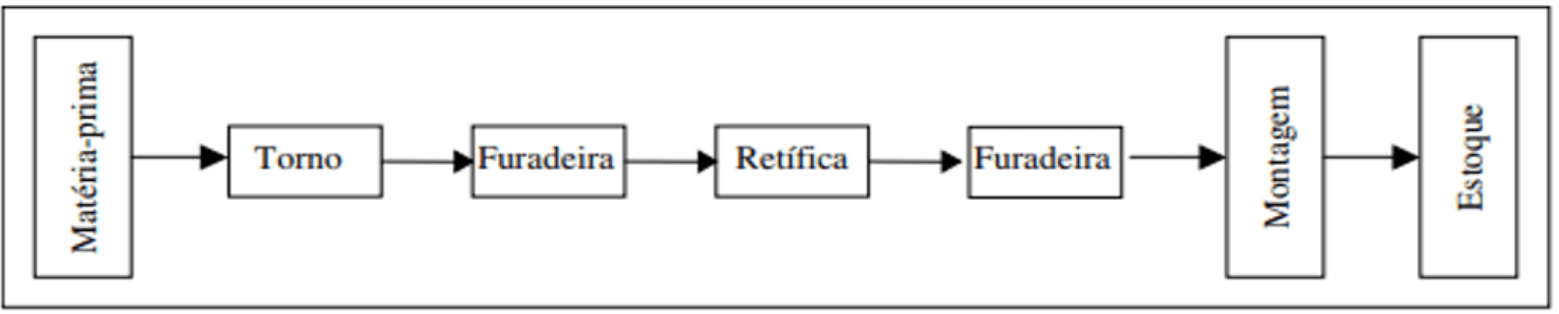

Fonte: Adaptado de ARGOUD (2007).

A representação da figura 3 , apresenta um fluxo contínuo e em um único sentido, da entrada da matéria-prima até ao produto final e seu armazenamento no estoque. A principal vantagem desse leiaute, segundo Argoud (2007), é obtido pelos processos controlados e facilidade na movimentação dos materiais.

- Leiaute celular os recursos transformados pré-selecionados são movimentados para as devidas células em que encontrarão os recursos necessários para o processamento, posteriormente são encaminhados para outra célula. O maquinário é agrupado de acordo com as operações ou familiaridades de peças, as movimentações são minimizadas devido a proximidades do processamento. A produção é em lotes menores, automatizada e rápida permitindo mudanças simples, e se faz necessário a presença do estoque. Exemplos de organizações de leiaute celular: Maternidade, manufaturas de computadores.

Figura 4 - Arranjo físico celular

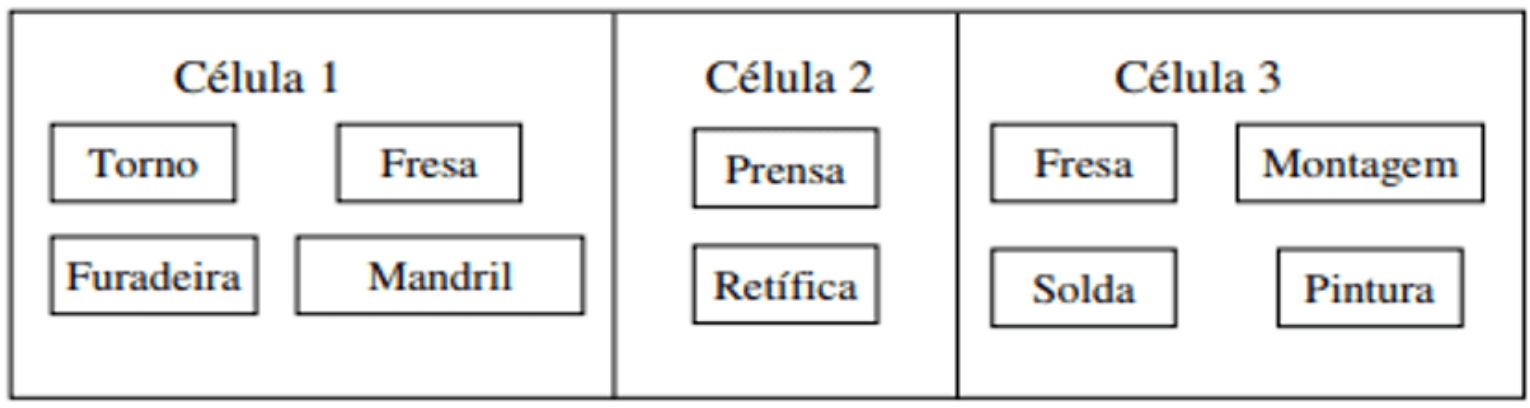

Fonte: Adaptado de ARGOUD (2007). 
A figura 4 apresenta a segmentação dos maquinários que realizam diferentes processos, onde são agrupadas peças similares no tocante às características físicas. Os itens são encaminhados para outras células e sofrem outro tipo de processamento.

- Leiaute misto ou híbrido é composto de vários tipos de leiautes operando no mesmo ambiente da organização. O hospital utiliza o leiaute de posição fixa, onde os equipamentos e serviços de atendimento são movimentados até o paciente, e o leiaute de processos, onde há a departamentalização dos diferentes processos para o atendimento, como a sala de radiografia.

Diante do exposto, conclui-se que o arranjo físico adotado pelas organizações está vinculado aos tipos de processamento dos materiais, das informações, aos tipos de produto acabado o que implica diretamente nas especificidades da mão de obra e dos equipamentos para a obtenção de melhores resultados, com o mínimo de esforços e custos operacionais envolvidos.

\subsection{RELAÇÕES ENTRE TIPOS DE PROCESSOS E TIPOS DE ARRANJO FÍSICO}

A organização tem como objetivo atender às necessidades dos clientes, para isso os processos produtivos são fundamentais para atingir a qualidade do produto ou serviços. De acordo com os autores, (LUSTOSA et al, 2008; MOREIRA, 1993; SLACK et al, 2009; TUBINO, 2007) o atendimento das expectativas dos clientes se dá por diversos fatores, considerados no processo produtivo, que são relacionados ao planejamento estratégico da empresa: custos, logística, cooperação entre os fornecedores, infraestrutura organizacional (leiaute). Dessa forma, analisaram a relação entre os processos produtivos e a disposição físicas das indústrias.

Segundo Slack et al (2009) o leiaute está vinculado ao processo produtivo pois é a manifestação física do mesmo, porém a escolha do tipo de leiaute para o processo está atrelada à característica do volume-variedade da operação, onde se verificará o objetivo da produção. Os custos afetam o volume produtivo, pois, quando há um 
grande volume de produção e pouca variedade de produtos, o resultado é a diluição dos custos.

Figura 5 - Posição do processo no contínuo volume - variedade.

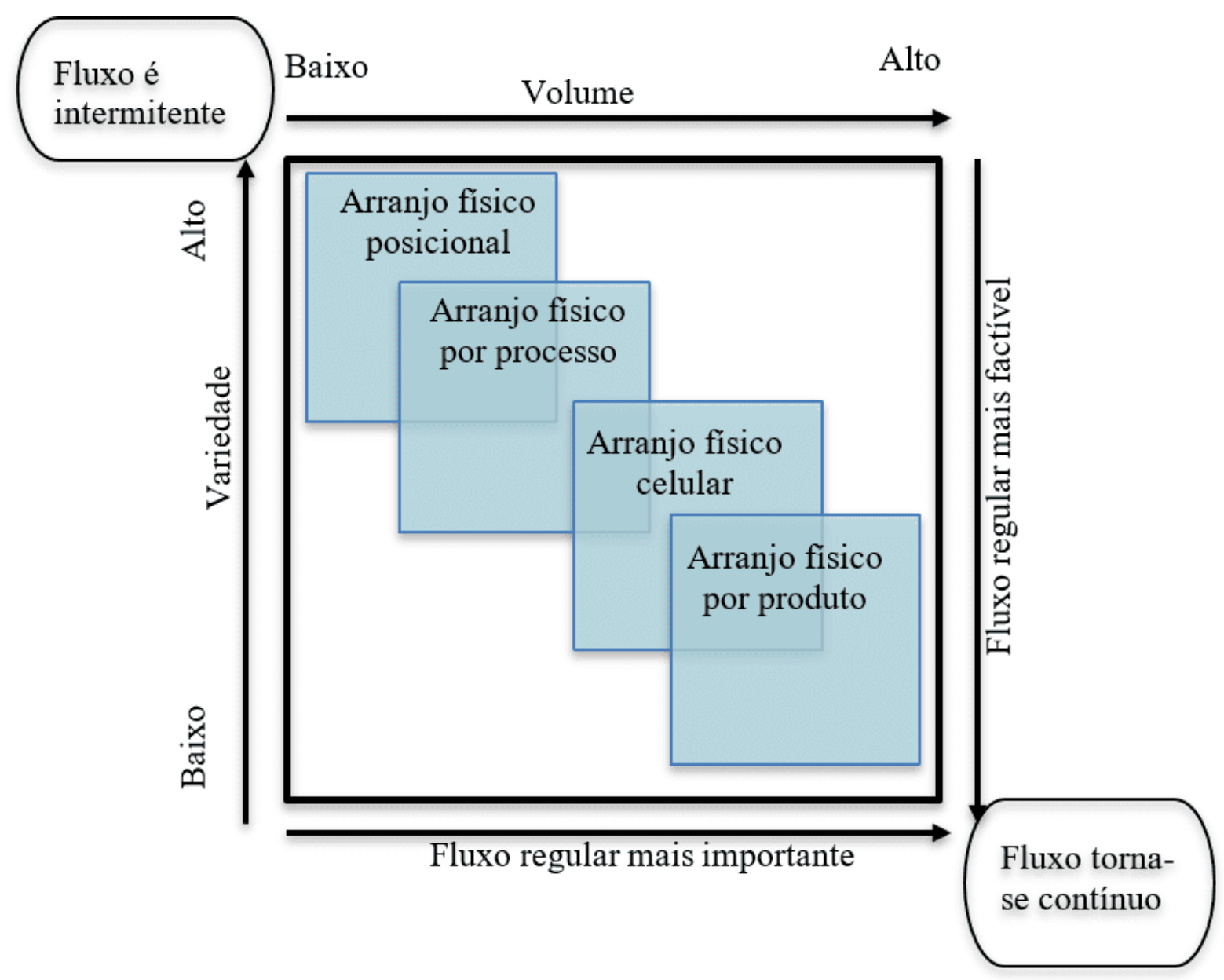

Fonte: SLACK et al (2009, p. 192)

A importância do fluxo para o arranjo físico é relacionada às características de volume e variedade do sistema produtivo. A exemplo de manufatura de baixo volume produtivo e alta variedade, o leiaute fixo é o mais indicado, onde ocorrerá pouco fluxo entre as operações. Em produções onde há alto volume e pouca variedade, o fluxo deve ser considerado. Para variedades menores, o fluxo é regularizado e o tipo de leiaute mais utilizado é o por produto. 
De acordo com Slack et al (2009) quanto maior o volume de produção, maior é a influência do fluxo na decisão do leiaute, quanto menor a variedade de produtos, mais o arranjo físico deve atentar às necessidades de processamento.

Para Moreira (1993), os arranjos físicos são classificados de acordo com os custos de equipamentos, manuseio de materiais ou movimentação de clientes, estoque de material em processo, entre outros. Dessa forma, os tipos de arranjo físico têm sua correspondência no sistema produtivo adotado, para o sistema de produção contínuo deve-se implantar o leiaute por produto, o leiaute por processo é o mais adequado à produção de lote ou sob encomenda, a produção realizada por projetos corresponde ao leiaute de posição fixa.

Segundo Tubino (2007) a relação dos sistemas produtivos em massa entre o arranjo físico é percebida pelas linhas de montagem, sendo abastecidas por insumos (supermercados). Para os sistemas repetitivos em lote, o leiaute celular, desenvolvido pelo Sistema Toyota de Produção, é o mais eficiente, onde os operadores polivalentes trabalham em pequenas linhas de montagens, dentro de um tempo de ciclo necessário que produz um fluxo unitário sem geração de estoques entre máquinas, resultantes da concentração de família de produtos.

Para Lustosa et al (2008) a implantação do leiaute industrial está condicionada ao sistema produtivo, onde verifica-se a demanda, variedade ou padronização dos produtos, volume de produção. A análise sob a influência do fluxo de informações pode ser classificada em: o leiaute por fluxo (flow shop) ou leiaute funcional (job shop). 
Figura 6 - Leiaute funcional (job shop)

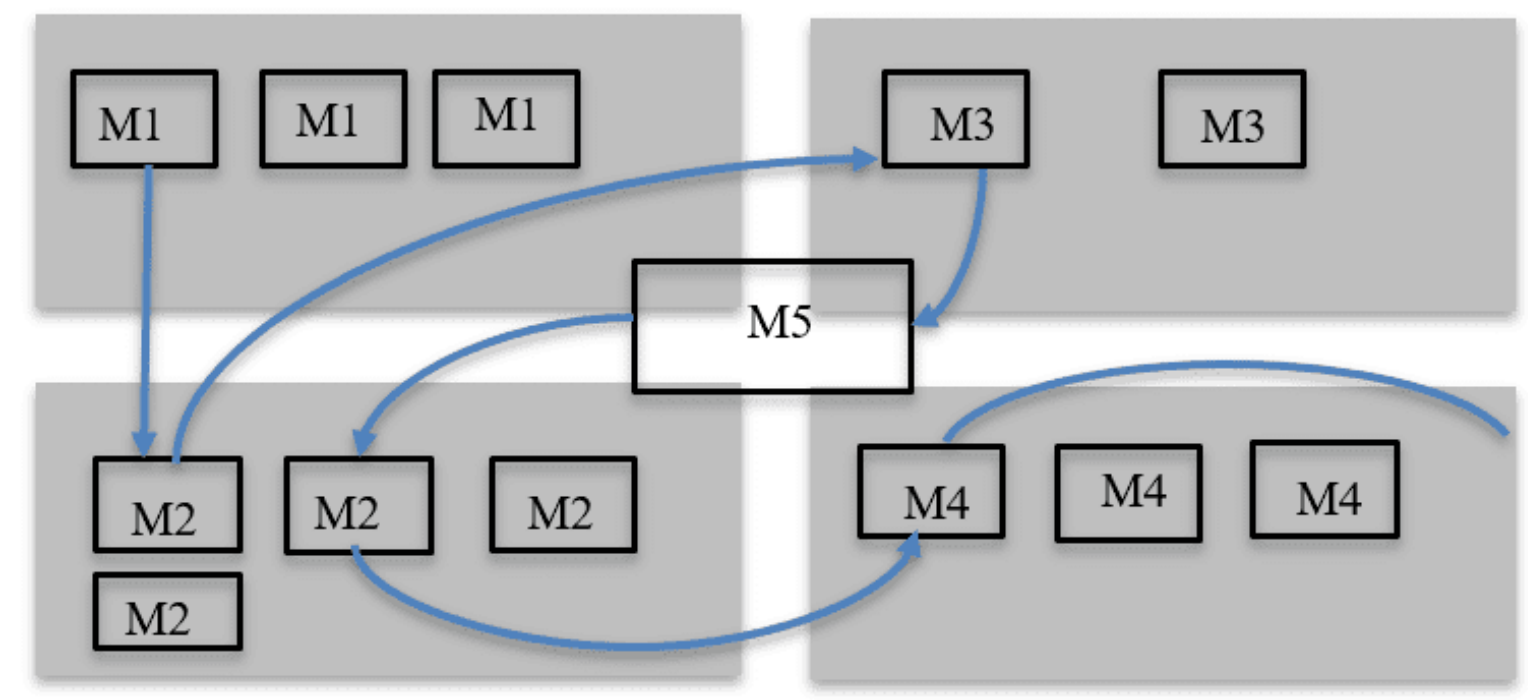

Fonte: LUSTOSA et Al (2008, p.20)

Figura 7 - Leiaute em fluxo (flow shop)

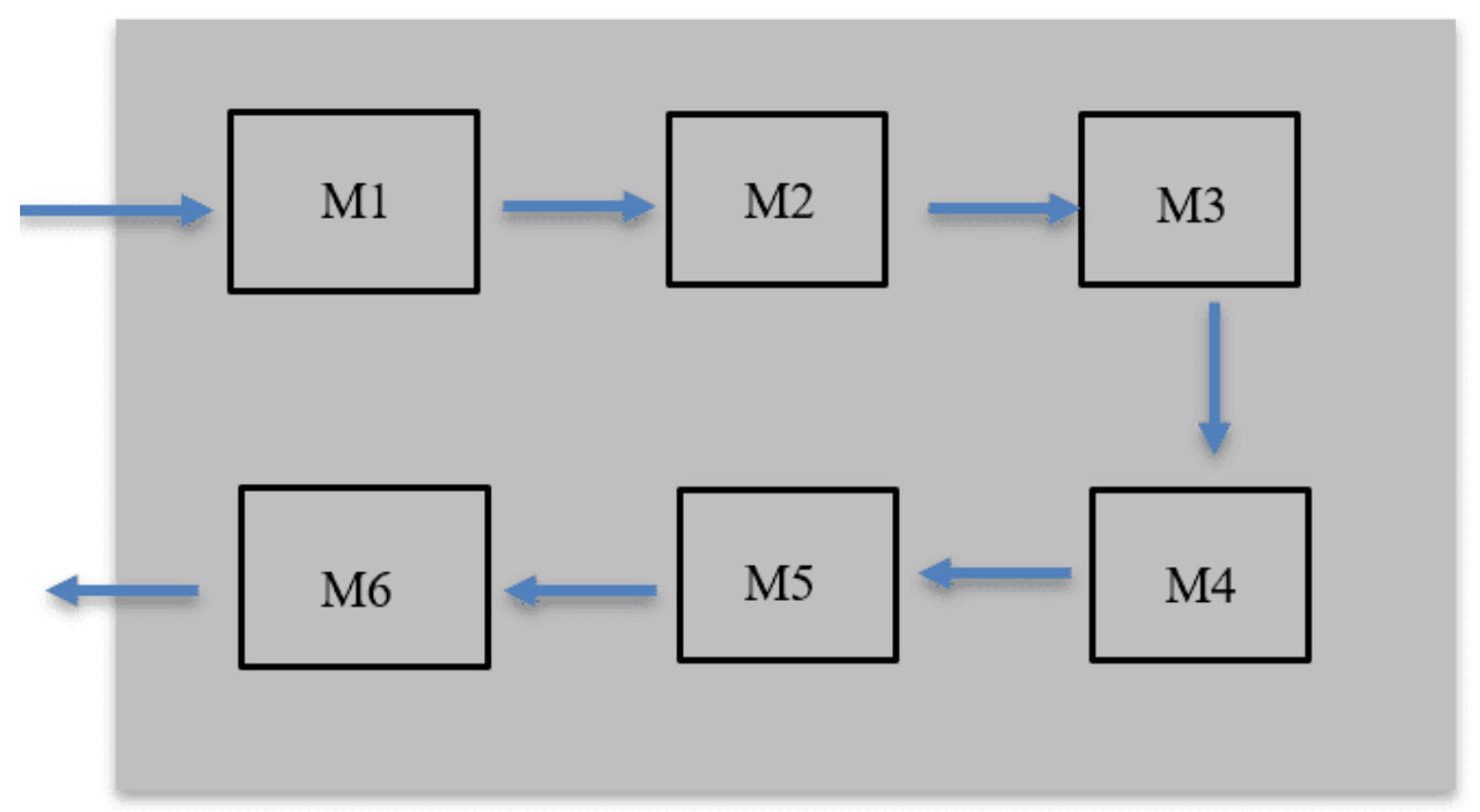

Fonte: LUSTOSA et al (2008, p. 20)

De acordo com Lustosa et al (2008), o leiaute funcional (job shop) é voltado para a produção por encomenda com baixos volumes de produção, alta variedade de produtos, fluxo irregular e tempo de produção maior, e quanto ao leiaute em fluxo ( flow 
shop), o mesmo é caracterizado por fluxo linear, alto volume e tempo curto de produção, alta padronização, produção repetitivas em lote.

Ante ao exposto pode-se concluir que a decisão do leiaute industrial está relacionada ao planejamento estratégico das organizações, onde a natureza do tipo de processo, que se consolidará pelas características do volume e variedades produtivas, são considerados, assim como os custos e o fluxo de informações, materiais e clientes.

\subsection{ESCOLHAS DOS TIPOS DE LEIAUTE PARA O PROCESSO PRODUTIVO}

Slack et al (2009) apontam que a decisão da escolha do tipo de leiaute para a implantação está baseada nas características de volume-variedade, a ponderação das vantagens e desvantagens que cada tipo de arranjo físico e o tipo de operação da manufatura que implicará a relação dos custos fixos e variáveis.

No tocante aos custos, Slack et al (2009) indicam que para o leiaute posicional, o custo fixo atrelado é baixo. De modo geral, os custos variáveis são relativamente altos para os outros tipos de leiaute. Ao transmutar os arranjos físicos, partindo do posicional, passando pelo celular e funcional, os custos fixos tendem a aumentar, em contraponto, os custos variáveis, a diminuir. Os custos totais dependem dos volumes produzidos, ou seja, os volumes referem-se a um leiaute básico que por sua vez acarreta um custo mínimo. No entanto, as variáveis dos custos que influem na decisão do leiaute são difíceis de quantificar. A variabilidade dos custos leva à incertezas na decisão do leiaute, sob essa hipótese, Slack et al (2009) concluem que a escolha deve ser baseada nas vantagens e desvantagens de cada tipo de leiaute, mostrada na tabela.

Tabela 1 - Vantagens e desvantagens dos tipos básicos de arranjo físico. 


\begin{tabular}{|c|c|c|}
\hline POSICIONAL & $\begin{array}{l}\text { Flexibilidade muito alta de mix } \\
\text { e produto. } \\
\text { Produto ou cliente não movido } \\
\text { ou perturbado. } \\
\text { Alta variedade de tarefas para } \\
\text { a mão de obra. }\end{array}$ & $\begin{array}{l}\text { Custos unitários muitos altos. } \\
\text { Programação de espaço ou } \\
\text { atividades pode ser complexa. } \\
\text { Pode significar muita } \\
\text { movimentação de equipamentos e } \\
\text { mão de obra. }\end{array}$ \\
\hline FUN & $\begin{array}{l}\text { Alta flexibilidade de mix e } \\
\text { produto. } \\
\text { Relativamente robusto em } \\
\text { caso de interrupção de etapas. } \\
\text { Supervisão de equipamento e } \\
\text { instalações relativamente fácil. }\end{array}$ & $\begin{array}{l}\text { Baixa utilização de recursos. } \\
\text { Pode ter alto estoque em processo } \\
\text { ou filas de clientes. } \\
\text { Fluxo complexo pode ser difícil de } \\
\text { controlar. }\end{array}$ \\
\hline CELULAR & $\begin{array}{l}\text { Pode dar um bom equilíbrio } \\
\text { entre custo e flexibilidade para } \\
\text { operações com variedade } \\
\text { relativamente alta. } \\
\text { Atravessamento rápido. } \\
\text { Trabalho em grupo pode } \\
\text { resultar em melhor motivação. }\end{array}$ & $\begin{array}{l}\text { Pode ser caro reconfigurar o } \\
\text { arranjo físico atual. } \\
\text { Pode requerer capacidade } \\
\text { adicional. } \\
\text { Pode reduzir níveis de utilização } \\
\text { de recursos. }\end{array}$ \\
\hline PRODUTO & $\begin{array}{l}\text { Baixos custos unitários para } \\
\text { altos volumes. } \\
\text { Dá oportunidade para } \\
\text { especialização de } \\
\text { equipamento. } \\
\text { Movimentação conveniente de } \\
\text { clientes e materiais. }\end{array}$ & $\begin{array}{l}\text { Pode ter baixa flexibilidade de mix. } \\
\text { Não muito robusto contra } \\
\text { interrupções. } \\
\text { Trabalho pode ser repetitivo. }\end{array}$ \\
\hline
\end{tabular}


Fonte: SLACK et al (2009, p 194)

As características atreladas à utilização de um tipo de arranjo físico dependem de quatro pontos fundamentais conforme detalhado na tabela, são eles: volume de produção, mão de obra especializada, maquinários e tecnologia e movimentação de materiais.

O volume produtivo afeta a decisão do tipo de leiaute, onde indica a diluição dos custos unitários para produção em larga escala, assim como a variedade do produto e tarefas a serem executadas pela mão de obra especializada, o tipo de movimentação pode ser complexo e as características dos equipamentos elevam o custo produtivo. Esses elementos indicam vantagens e desvantagens para os arranjos físicos.

Para Russel (2002 apudNEWMAN E SCALICE, 2017) ao escolher o leiaute adequado deve ser verificado o capital a ser investido, a alocação do armazenamento e estocagem, o nível de flexibilidade do sistema, o envolvimento dos equipamentos no que tange a manutenção e conhecimento técnico, a sociabilidade do ambiente, níveis das vendas para atendimento da demanda mercadológica.

Diante das informações apresentadas, conclui-se que na decisão do tipo de leiaute industrial, entre outras variáveis, deve-se considerar os custos variáveis e fixos do sistema produtivo de acordo com as vantagens que mais se adequam às necessidades da organização, e a utilização do estoque, infraestrutura do espaço e custos envolvidos para atendimento dos elos da cadeia de suprimentos.

\subsection{TIPOS DE LEIAUTE PARA ESTOQUE}

Segundo Viana (2010), os leiautes dos armazéns devem contribuir com os objetivos do uso do espaço eficientemente e movimentação rápida dos suprimentos, minimizar as despesas em relação a equipamentos, mão de obra e espaço, organização. $O$ leiaute determina o grau de acesso ao material, a forma como o fluxo será realizado, 
a localização de áreas obstruídas, operacionalização da mão de obra e segurança do armazém.

Ainda Viana (2010, p. 310) apresenta cincos passos para a desenvolvimento do projeto de um leiaute de um armazém:

1. Definir a localização de todos os obstáculos;

2. Localizar as áreas de recebimento e expedição;

3. Localizar as áreas primárias, secundárias, de separação de pedidos e de estocagem;

4. Definir o sistema de localização de estoque;

5. Avaliar as alternativas de leiaute do armazém.

Segundo Stevenson (2001), os principais aspectos observados para a composição do leiaute do armazém são:

- Itens de estoque: produtos de maior saída ou de grandes volumes devem ser colocados próximos à saída ou expedição.

- Corredores: Devem facilitar o acesso às mercadorias, para tanto equilibrar a quantidade de corredores com o espaço disponível de armazenamento, a largura deve determinada pelo tipo de equipamento de movimentação, devem estar localizados próximos às portas de acesso.

- Portas de acesso: dimensões adequadas para a movimentação dos materiais. O projeto da expedição deve prever um espaço de armazenagem temporário para o embarque e desembarque, e o acostamento para veículos deverá ser dimensionado para o volume diário das operações.

- Prateleiras e estruturas: A altura das prateleiras são dimensionadas de acordo com o peso dos materiais e a altura limite deverá ser de um metro de distância dos equipamentos instalados no teto da edificação. O piso do armazém deverá projetado a fim de receber altas cargas das mercadorias e de trânsito de equipamentos, materiais mais leves são localizados no topo das estruturas enquanto as mercadorias mais pesadas, no piso. 
O projeto do leiaute dos armazéns deve considerar a frequência dos pedidos, onde será disposto nas proximidades da saída, os itens mais frequentes e nos fundos, os itens menos frequentes, bem como materiais distintos, que são pedidos concomitantemente, devem ser dispostos próximos dentro do armazém, sendo que essas medidas irão diminuir o deslocamento, induzindo a redução dos custos (STEVENSON, 2001) e os principais fatores a serem considerados no projeto do armazém são: as quantidades e larguras das alas (corredores), altura das estruturas, forma da expedição e armazenamento, modal de transporte e a periodicidade dos inventários dos materiais.

Ante ao exposto, o leiaute dos armazéns, além de facilitar a operacionalidade do recebimento e expedição através de dimensionamento adequado para armazenar e movimentar os materiais, deve prever a forma do atendimento ao cliente eficientemente de maneira que a infraestrutura do espaço não onere os custos do produto.

\section{CONSIDERAÇÕES FINAIS}

A análise das tipologias para os sistemas produtivos é de suma importância para o planejamento estratégico das organizações a fim de programar o atendimento da demanda objetivando a satisfação do cliente.

No presente trabalho foram analisadas as características dos sistemas produtivos, visando verificar as especificidades e classificações da operação no ambiente industrial e a inter-relação entre as tipologias dos arranjos físicos.

Para realizar a correlação do leiaute com o sistema produtivo é necessário o conhecimento das características de cada tipo de arranjo físico para posteriormente traçar as afinidades em ambos para auxiliar na decisão do leiaute mais adequado à necessidade da empresa.

Nessa análise observou-se que as características mais comuns tanto para o processo produtivo como para o arranjo físico, são: volume, variedade, fluxos, maquinários, 
tempo de produção, custos e mão de obra, o que indica a estreita relação entre os aspectos dos processos produtivos e sua conformação no espaço. No entanto, Slack et al (2009) apontam que as principais variáveis que influem no projeto são os volumes e variedades produtivas, onde afetam o fluxo entre as operações, assim como o trânsito de materiais, clientes e informações que devem ser contabilizados no espaço físico.

Em consonância com as variáveis de volume-variedade e fluxo, Slack et al (2009) justificam a escolha do leiaute para os sistemas produtivos: para os processos contínuos e os repetitivos em massa é indicado o leiaute por produto, os processos repetitivos em lote ou encomenda deve ser projetado o leiaute por processo ou celular, e o leiaute por posição é recomendado para as produções por projeto.

No que se refere aos custos, baseado nas proposições dos autores, a variedade dos produtos ou personalização diminuem os custos fixos de produção, em contraponto os custos variáveis podem aumentar, a exemplo do leiaute posicional, que possui alta variedade e menores custos fixos. Ao programar a produção para produtos padronizados em larga escala, os custos fixos aumentam e os custos variáveis diminuem. Segundo Slack et al (2009), o custo é a decisão mais complexa para se pautar no arranjo físico devido a sua volatilidade.

Ao projetar o arranjo físico da indústria deve-se contabilizar os investimentos em infraestrutura, equipamentos e recursos humanos, escolher o sistema produtivo por meio das características que mais favorecem o planejamento estratégico da organização, tangendo o nível de serviço para o cliente, sendo que a escolha do sistema produtivo afeta na decisão do leiaute a ser implantado, que deve ser baseado na observância das vantagens e desvantagens que emergem a tipologia do arranjo físico mediante a produção, além das questões espaciais como o dimensionamento dos espaços de circulação, locação dos maquinários, estrutura das instalações, entre outros ( SLACK et al, 2009). 


\section{REFERÊNCIAS}

ARGOUD, Ana Rita Tiradentes Terra. Procedimento para projeto de arranjo físico modular em manufatura através de algoritmo genético de agrupamento. 2007. Tese de Doutorado. Universidade de São Paulo.

GAITHER, N.; FRAZIER, G. Administração da produção e operações. $8^{a}$ ed. São Paulo: Cengage Learning, 2012.

GONÇALVES FILHO, E. V. Arranjo Físico de Fábrica: um modelo para o processo de projeto e algoritmo genético para a formação de células de fabricação. Tese de doutorado - Escola de Engenharia de São Carlos. Universidade de São Paulo. São Carlos. 2001.

LUSTOSA, L.; MESQUITA, M. A.; QUELHAS, O.; OLIVEIRA, R. Planejamento e Controle da Produção. Rio de Janeiro: Elsevier, 2008.

MOREIRA, D. A. Administração da Produção e Operações. Editora Pioneira. São Paulo, 1993. (2ª edição revista e ampliada)

NEUMANN, Clóvis; SCALICE, Regis. Projeto de fábrica e leiaute. Elsevier Brasil, 2017.

PIRES, S. RI. Gestão da cadeia de suprimentos (supply chain management): conceitos, estratégias, práticas e casos. Atlas, 2009.

SLACK, N.; CHAMBERS, S.; JONHNSTON, R. Administração da produção. 3. ed. São Paulo: Atlas, 2009.

STEVENSON, W. J. Administração das operações de produção. 6ª ed. LTC, 2001.

TUBINO, D. F. Planejamento e controle da produção: teoria e prática. $2^{\underline{a}}$ ed. São Paulo: Atlas, 2007. 
VIANA, J. J. Administração de materiais: um enfoque prático. $1^{\underline{a}}$ ed. São Paulo: Atlas, 2010.

Enviado: Agosto,. 2019.

Aprovado: Janeiro, 2020. 